\title{
Exportaciones verdes en Barbados: Una evaluación de sus potencialidades
}

Winston Moore

RESUMEN

La transición hacia una economía verde, centrada en reducir los riesgos ambientales y la escasez de recursos sin dejar de contribuir al bienestar, se ha propuesto como una vía posible de desarrollo sostenible. Si bien son claras las ventajas potenciales de emprender el camino del desarrollo verde, el avance en este sentido requiere garantizar el apoyo a las empresas e industrias emergentes. En consecuencia, el programa de políticas tendrá que adaptarse a estas nuevas esferas de negocios verdes. En este estudio se hace una valoración de diversas empresas verdes y su posible idoneidad para el pequeño Estado insular de Barbados. 


\section{I}

\section{Introducción}

Debido a que tiene un tipo de cambio fijo, para financiar sus importaciones Barbados depende de los ingresos en divisas procedentes de la exportación de bienes y servicios. Las importaciones se utilizan prácticamente en todos los procesos de la producción, desde el turismo hasta las manufacturas. En 2010, las exportaciones totales de mercaderías ascendieron a 429 millones de dólares, equivalentes a menos del $1 \%$ del total de las exportaciones mundiales. Como se indica en el cuadro I.1, las exportaciones de Barbados se concentraban en unas pocas esferas clave, principalmente en productos agrícolas y manufacturas. La mayoría de esas exportaciones se destinan a los Estados Unidos (25\%) y la Unión Europea $(20,4 \%)$. Mientras tanto, en 2010, las exportaciones totales de servicios alcanzaron los 1.600 millones de dólares, lo que representaba alrededor del $0,04 \%$ del total de las exportaciones mundiales. Estas modalidades de intercambio comercial responden no solo a factores geográficos (como la cercanía a los Estados Unidos), sino a pautas históricas (por ejemplo, la exportación de azúcar a Europa en el marco de acuerdos comerciales preferenciales). Corresponde al sector de los viajes la mayor parte de los ingresos en concepto de exportaciones (67\%) y la proporción restante consiste mayormente en otros servicios comerciales.

Dada la concentración relativamente elevada de las exportaciones de la isla (tanto de bienes como de servicios) en unos pocos sectores clave, la exportación de bienes y servicios verdes podría representar una oportunidad de diversificación hacia sectores de mayor valor agregado. De hecho, en 2011 el Primer Ministro Freundel Stuart ${ }^{1}$ señaló que uno de los objetivos de desarrollo de la isla a mediano y largo plazo sería convertirse en el país de América Latina y el Caribe más verde y avanzado en términos ambientales. Para lograr dicho objetivo, en la isla se concluyó un estudio sobre el alcance de la economía verde (Moore y otros, 2012), con una valoración

\footnotetext{
${ }^{1}$ Discurso pronunciado en la inauguración de la Asociación entre el Gobierno de Barbados y el Programa de las Naciones Unidas para el Medio Ambiente (PNUMA), que tuvo lugar en la Facultad de Ciencias Médicas de la Universidad de las Indias Occidentales y cuyo fin fue establecer en Barbados una economía verde y eficiente en cuanto al uso de recursos.
}

CUADRO 1

Barbados: principales productos de importación y exportación, 2010

(En dólares)

Productos

Valor comercial

\section{Importaciones}

Combustibles minerales, aceites minerales y productos de su destilación

484333718

Máquinas, aparatos mecánicos y sus partes

Máquinas, aparatos y material eléctrico y sus partes, aparatos de grabación o reproducción de sonido, aparatos de 110024097 grabación o reproducción de imágenes y sonido en televisión, y las partes y accesorios de estos aparatos

Vehículos, excepto material rodante de ferrocarriles y tranvías

Otros productos

\section{Exportaciones}

Combustibles minerales, aceites minerales y productos de su destilación 
de las posibles oportunidades de seguir una estrategia de crecimiento verde. Una de las recomendaciones del estudio es que se debería efectuar una evaluación del comercio de bienes y servicios ambientales en Barbados, para que la isla pueda aprovechar plenamente el potencial de la economía verde.

De este modo, en el presente documento se intenta determinar las oportunidades de Barbados en materia de exportación verde de bienes y servicios. En cuanto a los bienes, se utiliza el proyecto de lista del universo de bienes ambientales de la Organización Mundial del Comercio (OMC, 2011) para identificar las áreas en que la isla posee ventajas comparativas $\mathrm{y}$, en cuanto a los servicios, se presenta una valoración de hasta qué punto las posibles oportunidades de negocios verdes coinciden con el entorno empresarial de Barbados. Los resultados del estudio podrían tenerse en cuenta en la formulación de políticas industriales, fiscales y de comercio. En lo que respecta a la política comercial, este ejercicio podría emplearse como estudio de caso acerca de las posibles implicaciones de aceptar el proyecto de lista del universo de bienes ambientales de la omc. En los casos en que se determine la existencia de posibles ventajas comparativas, los encargados de la formulación de políticas podrían estimular el crecimiento en esas esferas mediante la aplicación de incentivos y el apoyo de un marco adecuado de políticas industriales ${ }^{2}$.

${ }^{2}$ Esto podría lograrse mediante actividades de educación y capacitación, acceso al crédito para los empresarios, tutorías y acceso a exposiciones
Entre los estudios más afines que se encuentran en la bibliografía existente sobre el tema están los de Huberty y Zachmann (2011) y Ernst y Young (2008). Sin embargo, a diferencia de lo planteado por Huberty y Zachmann, en el presente trabajo no se pretende definir cuáles son los bienes verdes, sino utilizar el proyecto de lista de la OMC para determinar la existencia de posibles ventajas comparativas. Este análisis pudiera ser pertinente para los negociadores comerciales que examinan los posibles efectos que tendría la aceptación de esta lista en el comercio de Barbados (y, hasta cierto punto, en toda la región del Caribe). El documento se distingue además de los de Huberty y Zachmann (2011) y Ernst y Young (2008), en que contempla las posibles oportunidades tanto en el comercio de mercaderías como en el de servicios.

El resto del estudio se estructura de la siguiente manera: tras la Introducción, en la sección II se examina el concepto de bienes y servicios verdes y se intenta mostrar la relación entre las diversas definiciones que se emplean actualmente. En la sección III se esboza el enfoque metodológico empleado para evaluar las posibles oportunidades de exportación verde y en la sección IV se presentan los resultados. En la sección $\mathrm{V}$ se resumen las conclusiones principales y se proponen algunas recomendaciones sobre cambios de políticas en el futuro.

comerciales. Muchos de estos incentivos ya están disponibles en Barbados, pero no se destinan específicamente a los bienes verdes.

\section{II}

\section{Determinación de los bienes y servicios verdes}

Los términos "bienes y servicios verdes" y "bienes y servicios ambientales" se emplean indistintamente en la bibliografía pertinente. Según la Organización de Cooperación y Desarrollo Económicos (OCDE/EUROSTAT, 1999), la industria de bienes y servicios ambientales se compone en gran medida de actividades en que se producen bienes y servicios destinados a cuantificar, prevenir, limitar, reducir o corregir los daños ambientales que afectan al agua, el aire y el suelo, y los problemas relacionados con los residuos, el ruido y los ecosistemas. En esa definición se establecen categorías de bienes y servicios según su vínculo con la gestión de la contaminación, las tecnologías y productos menos contaminantes o la gestión de los recursos. En cada categoría las actividades se clasifican además en tres subgrupos: i) producción de equipos y materiales específicos; ii) prestación de servicios, y iii) construcción y puesta en marcha de instalaciones (véase el gráfico 1).

Sin embargo, la definición de la industria de bienes y servicios ambientales no está aún exenta de polémica y, según Sinclair-Desgagné (2008), invade el ámbito de otras clasificaciones industriales más conocidas. Por ejemplo, en lugar de incluir las células fotovoltaicas, los molinos de viento y el etanol en el sector de la energía, y definir el ecoturismo como una subcategoría del turismo, estos elementos se incluirían en la industria 
GRÁFICO 1

Categorías de bienes y servicios ambientales según la OCDE y la EUROSTAT
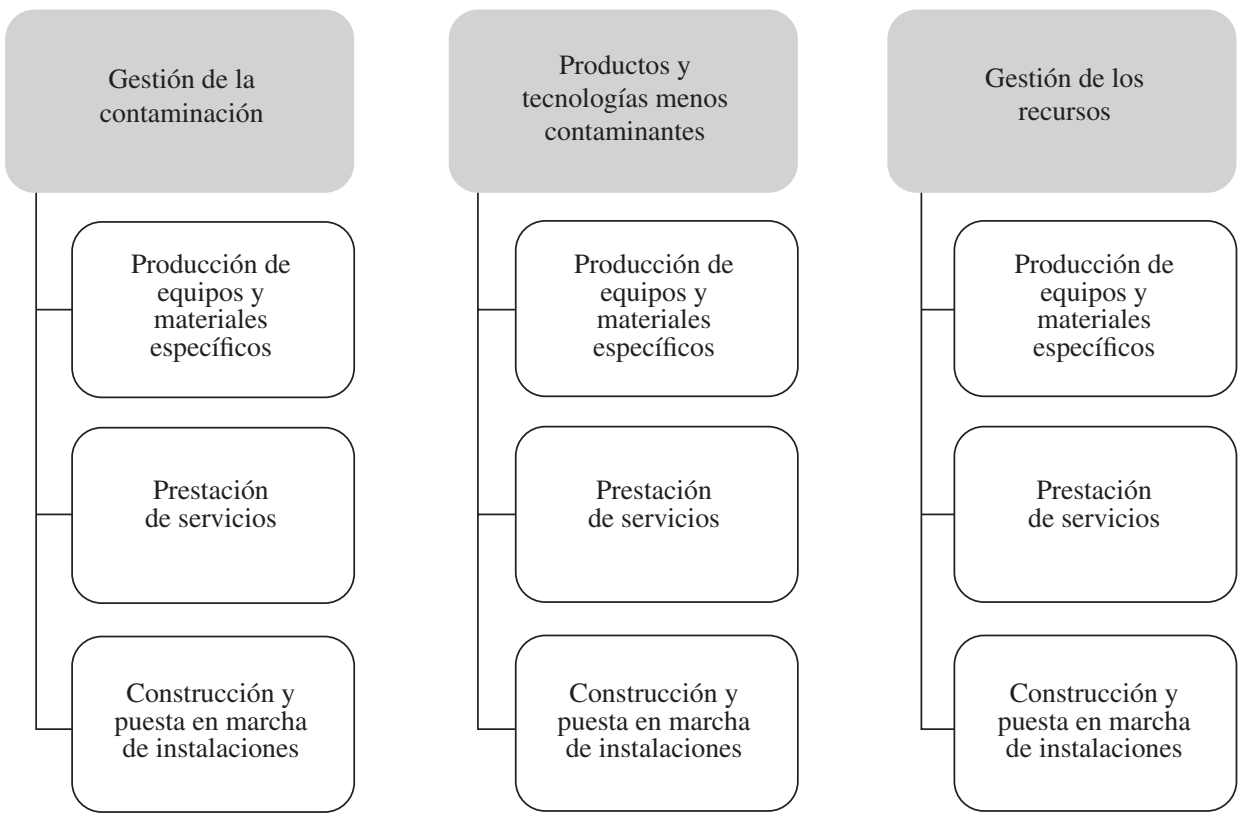

Fuente: Organización de Cooperación y Desarrollo Económicos/Oficina de Estadística de las Comunidades Europeas (OCDE/EUROSTAT), The Environmental Goods and Services Industry: Manual for Data Collection and Analysis, París, oEcD Publishing, 1999.

de bienes y servicios ambientales. La distinción entre bienes y servicios ambientales y no ambientales también es un tanto ambigua. Por ejemplo, no está claro si todas las mejoras tecnológicas y de gestión que aumentan la eficiencia en el uso de recursos deberían incluirse en la clasificación de los bienes y servicios ambientales.

Sobre la base de este trabajo inicial, la Oficina de Estadísticas Laborales del Departamento de Trabajo de los Estados Unidos de América emplea una definición similar a la elaborada por la OCDE/EUROSTAT (1999), al establecer que las empresas verdes son aquellas que se ocupan de la producción o la prestación de servicios que contribuyen a mejorar el medio ambiente o conservar los recursos naturales (Oficina de Estadísticas Laborales, 2012). Sin embargo, la Oficina de Estadísticas Laborales intenta hacer frente a algunas de las críticas que se han hecho a la ocDE/EURostat (1999) mediante la presentación de orientaciones claras en cuanto a las empresas de servicios ambientales y la conservación de los recursos naturales. En el gráfico 2 se presentan las diversas categorías de productos verdes que ha establecido la Oficina de Estadísticas Laborales, junto con las subcategorías correspondientes.

La Oficina de Estadísticas Laborales establece una distinción entre los bienes y servicios verdes y otros bienes o servicios similares según si en ellos se aplican normas federales (por ejemplo, la certificación de productos orgánicos por parte del Departamento de Agricultura de los Estados Unidos de América o el programa Energy Star, implementado por la Agencia de Protección Ambiental de los Estados Unidos) o normas industriales de amplio uso (como las del programa Liderazgo en Energía y Diseño Ambiental (LEED, por sus siglas en inglés)). Si bien el uso de estas normas industriales y nacionales es una respuesta a las críticas sobre el sistema de clasificación relativamente arbitrario que utiliza la OCDE/EUROSTAT (1999), este nuevo enfoque sigue sin resolver la cuestión subyacente del umbral para la entrada: ¿a partir de qué momento se considera que una empresa o un producto son verdes?

En lugar de adoptar una definición amplia de bienes y servicios verdes, la República de Corea ha concentrado su Nuevo Pacto Verde en 27 actividades esenciales de alta tecnología ${ }^{3}$. El plan tiene por objeto desarrollar una economía en que los recursos se aprovechen de manera

\footnotetext{
${ }^{3}$ El Nuevo Pacto Verde de la República de Corea es un plan de estímulo establecido en 2009, en respuesta a la recesión, para estimular el crecimiento a corto plazo y reorientar la economía a mediano y largo plazo hacia sectores más eficientes en el uso de recursos.
} 

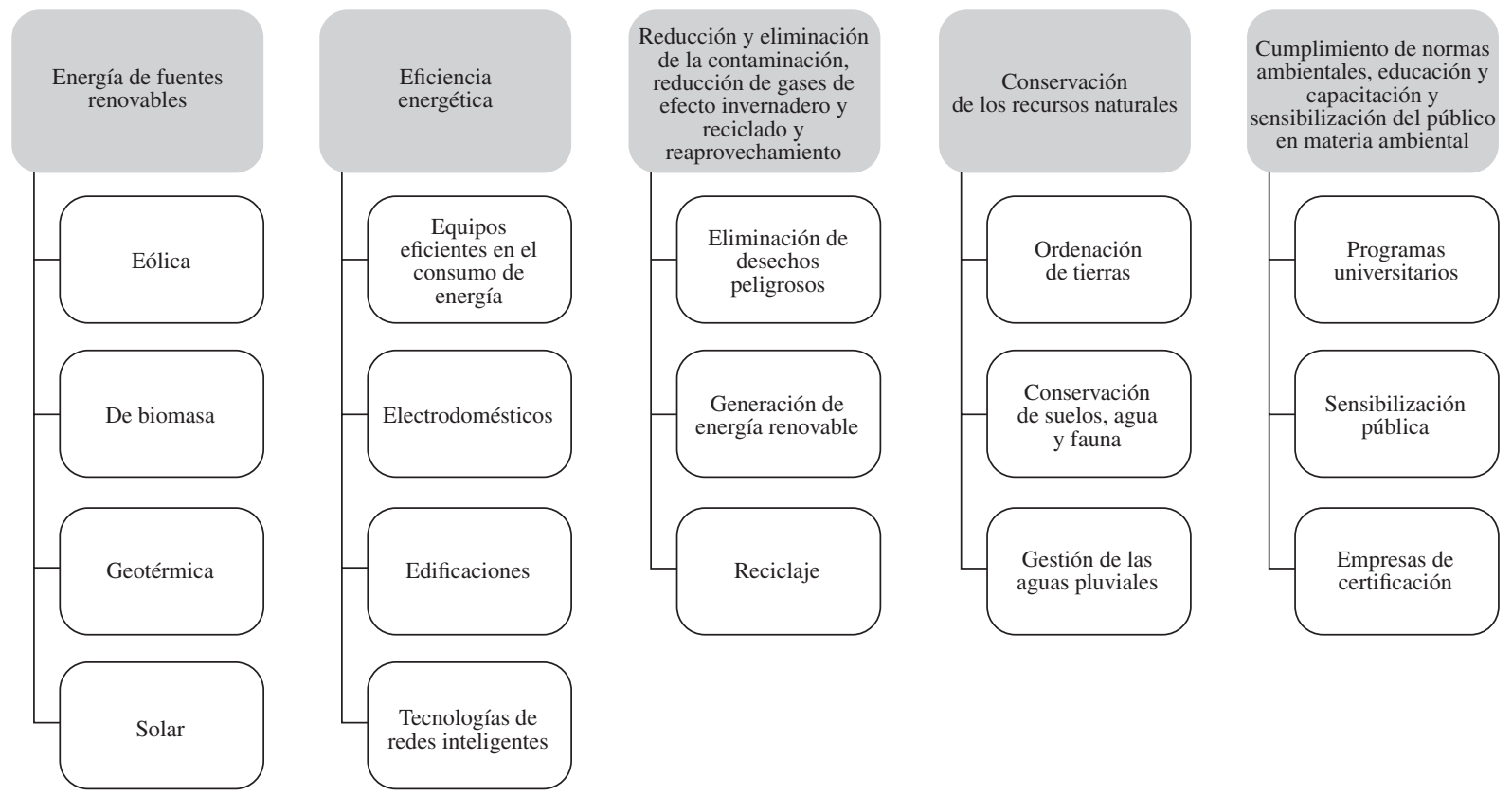

Fuente: Oficina de Estadísticas Laborales , "Green Goods and Services”, Departamento del Trabajo de los Estados Unidos, 2012 [en línea] http://www.bls.gov/ggs/ggsoverview.htm

eficiente con un mayor volumen de producción a largo plazo. Cada tipo de inversión se clasifica con arreglo a su marco temporal: i) gradual a corto plazo; ii) intensiva a mediano plazo, e iii) intensiva a largo plazo (véase el gráfico 3). En el gráfico 3 se muestran las principales categorías de exportación, el tipo de productos y servicios beneficiados y la naturaleza de las inversiones en función de si se refieren a objetivos a corto, mediano o largo plazo. Si bien la selección de las industrias que deberán recibir apoyo en el marco del Nuevo Pacto Verde de la República de Corea parece un tanto limitada, constituye un claro mensaje para el sector privado acerca de las esferas a las que probablemente se destine la ayuda del gobierno en la actualidad y en el futuro. Aunque estas 27 esferas esenciales no se definieron con fines de medición, no dejan lugar a duda en cuanto a los sectores que el gobierno considera verdes.

Una definición alternativa del concepto de productos verdes se puede extraer del ámbito del comercio internacional. El objetivo central del Programa de Doha para el Desarrollo presentado en la cuarta Conferencia Ministerial de la Organización Mundial del Comercio (OMC) es aumentar el apoyo a las políticas comerciales y ambientales. En la actualidad se realizan negociaciones en tres esferas fundamentales: i) La relación entre las normas de la OMC y los acuerdos multilaterales sobre el medio ambiente;

ii) La colaboración entre la OMC y las secretarías de dichos acuerdos multilaterales;

iii) La eliminación de los obstáculos arancelarios y no arancelarios al comercio de bienes y servicios ambientales.

En cuanto a la tercera esfera mencionada, los miembros de la OMC están realizando negociaciones acerca de la forma de definir los bienes ambientales, pero aún no han abordado la definición de servicios. Se han presentado varias propuestas en relación con los bienes: en una de ellas se exhorta a utilizar criterios amplios para su determinación; en otra se sugiere implantar un procedimiento de solicitud y oferta, en que los miembros propondrían los productos que deberían incluirse y respecto de los cuales estén preparados para asumir compromisos de liberalización. Según una tercera propuesta, se elaborarían dos listas, una para los países desarrollados y la otra para los países en desarrollo sobre la con base de un solo universo de bienes; o de lo contrario, podría elaborarse una lista común para todos los miembros y una segunda lista que solo comprendería los productos seleccionados concretamente por los países en desarrollo para la 
República de Corea: categorías de bienes y servicios verdes

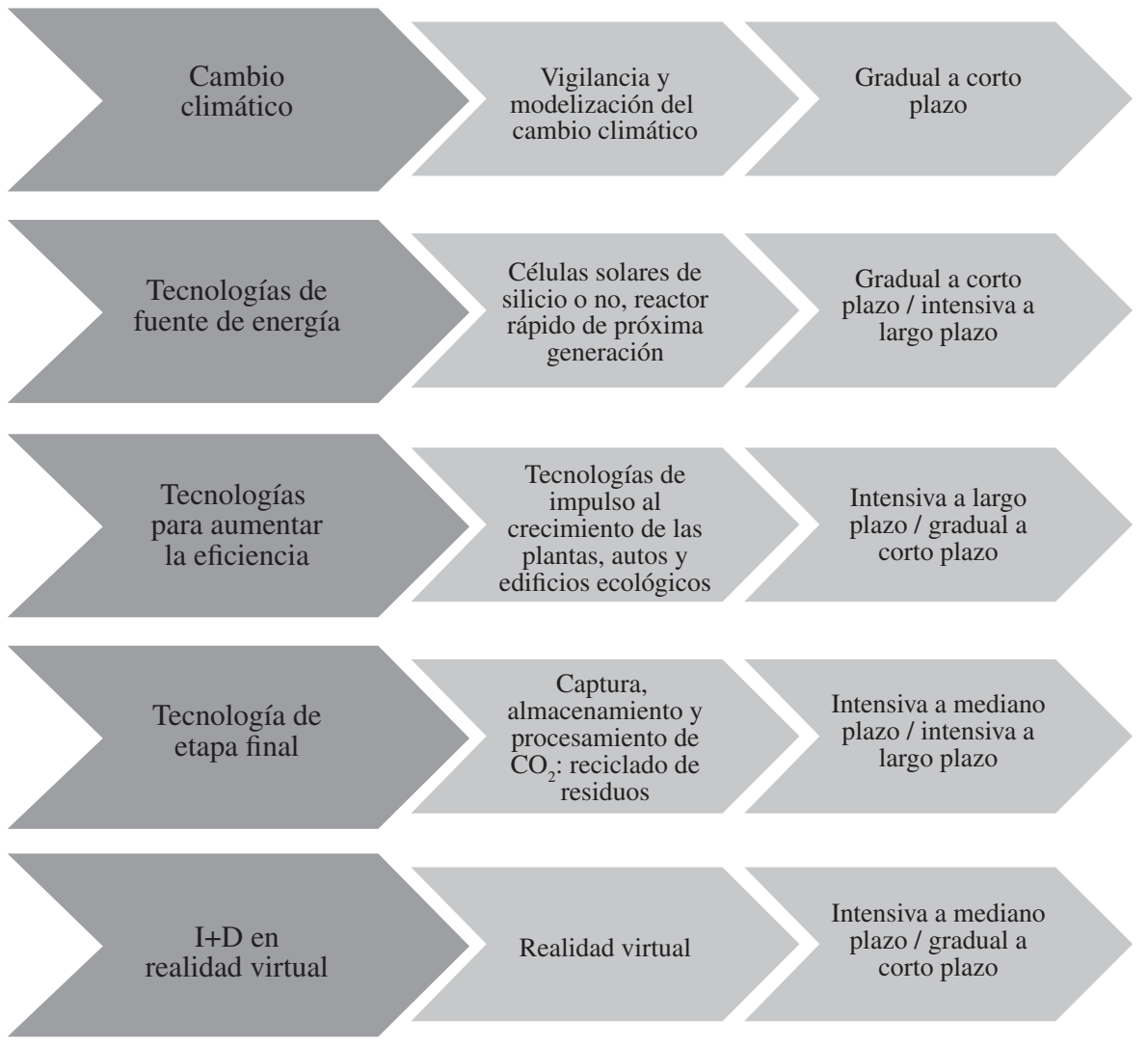

Fuente: Banco Mundial, "Lessons from the Implementation of Republic of Korea’s Green Stimulus", INFra Update, 2010 [en línea] http:// siteresources.worldbank.org/INTSDNET/Resources/5944695-1247775731647/INFRA_Korea_Newsletter.pdf.

I+D: investigación y desarrollo.

aplicación de exenciones o de un nivel más bajo de trato arancelario. El gráfico 4 contiene una versión general del proyecto de lista referencial del universo de bienes y servicios ambientales.

El universo referencial se basa en la revisión de 2002 de la clasificación del Sistema Armonizado de Designación y Codificación de Mercancías (sA 2002) al nivel de seis dígitos y se puede obtener de la omC (2011). Como punto de partida para el examen, se ha propuesto como muestra una lista esencial de bienes (véase el cuadro 2).

Sin un acuerdo internacional, estos bienes y servicios verdes seguirán siendo objeto de iguales obstáculos arancelarios y no arancelarios al comercio que otros bienes y servicios de menor eficiencia en cuanto al uso de recursos. No obstante, en el estudio sobre el alcance de la economía verde (Moore y otros, 2012) relativo a Barbados se observa que, dadas las limitaciones ambientales que enfrenta la isla y la demanda de oportunidades de empleo digno, una estrategia de crecimiento verde tendría un potencial importante como forma de contribuir al crecimiento y al desarrollo sostenibles. Sobre esta base, en la sección siguiente se esboza un posible enfoque respecto de la clasificación de las diversas oportunidades en materia de exportaciones ecológicas que deberían tener en cuenta los encargados de la formulación de políticas en cuanto al apoyo normativo en el futuro. 


\section{Proyecto de lista del universo referencial de bienes ambientales}
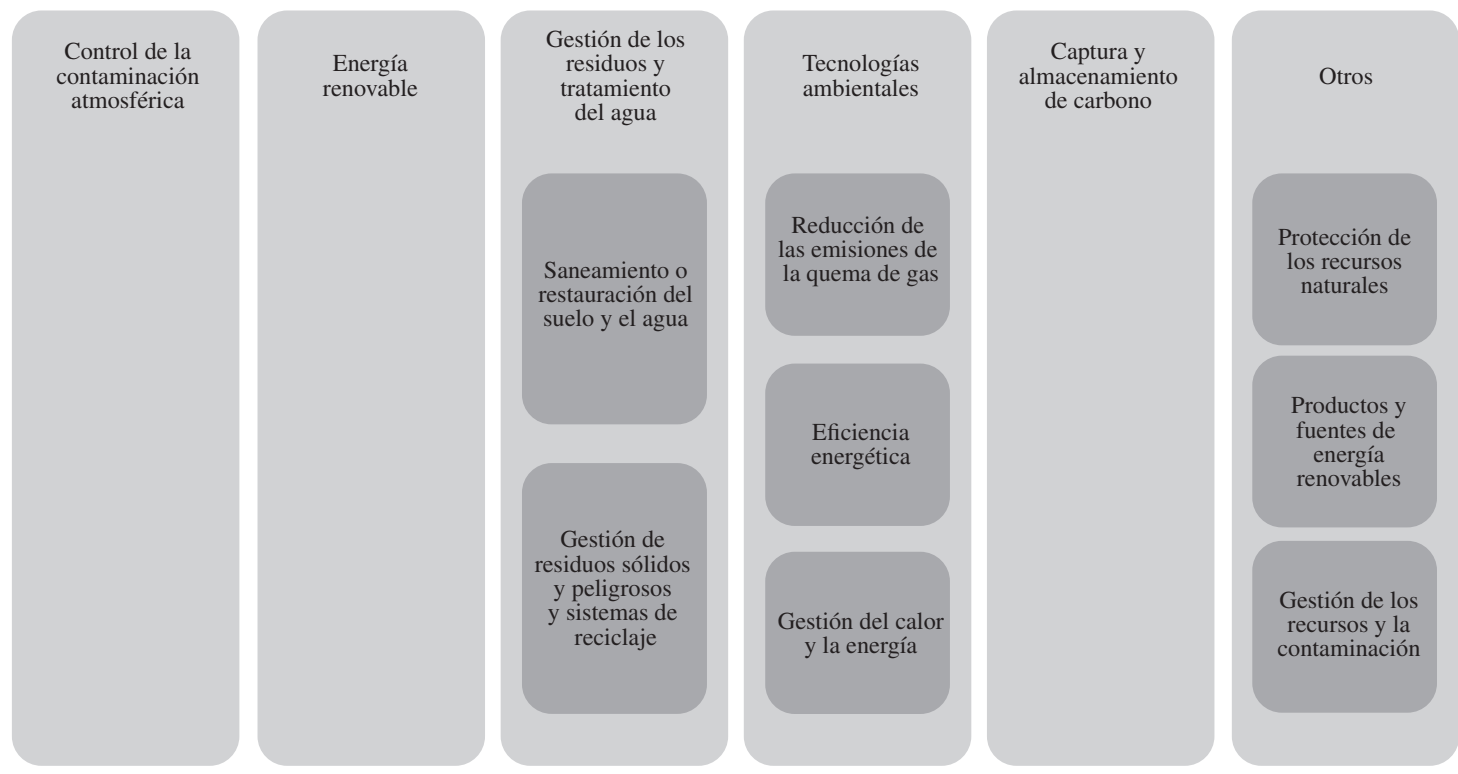

Fuente: Organización Mundial del Comercio (омc), Report by the Chairman, Ambassador Manuel A.J. Teehankee, to the Trade Negotiations Committee, Ginebra, Comité de Comercio y Medio Ambiente, 2011.

CUADRO 2

\section{Lista esencial de muestra de bienes ambientales}

\section{Código}

del SA 2002

Descripción

Categoría y subcategoría

\begin{tabular}{|c|c|c|}
\hline 4601 & $\begin{array}{l}\text { Trenzas y artículos similares, de materia trenzable, } \\
\text { incluso ensamblados en tiras; materia trenzable, trenzas } \\
\text { y artículos similares de materia trenzable, tejidos o } \\
\text { paralelizados, en forma plana, incluso terminados }\end{array}$ & \\
\hline 460120 & - Esterillas, esteras y cañizos, de materia vegetal & $\begin{array}{l}\text { Gestión de residuos y tratamiento de agua: } \\
\text { - Gestión de residuos, reciclado y restauración del medio } \\
\text { ambiente }\end{array}$ \\
\hline 7308 & $\begin{array}{l}\text { Construcciones y sus partes (por ejemplo: puentes y } \\
\text { sus partes, compuertas de esclusas, torres, castilletes, } \\
\text { pilares, columnas, armazones para techumbre, techados, } \\
\text { puertas y ventanas y sus marcos, contramarcos y } \\
\text { umbrales, cortinas de cierre, barandillas), de fundición, } \\
\text { hierro o acero, excepto las construcciones prefabricadas } \\
\text { de la partida } 94.06 \text {; chapas, barras, perfiles, tubos y } \\
\text { similares, de fundición, hierro o acero, preparados para } \\
\text { la construcción. }\end{array}$ & \\
\hline 730820 & - Torres y castilletes & $\begin{array}{l}\text { Energía renovable } \\
\text { Otros: } \\
\text { - Productos y fuentes de energía renovables }\end{array}$ \\
\hline 7321 & $\begin{array}{l}\text { Estufas, calderas con hogar, cocinas (incluidas las } \\
\text { que puedan utilizarse accesoriamente para calefacción } \\
\text { central), barbacoas (parrillas), braseros, hornillos de } \\
\text { gas, calientaplatos y aparatos no eléctricos similares, } \\
\text { de uso doméstico, y sus partes, de fundición, hierro o } \\
\text { acero }\end{array}$ & \\
\hline 732111 & $\begin{array}{l}\text { - Aparatos de cocción y calientaplatos: de combustibles } \\
\text { gaseosos o de gas y otros combustibles }\end{array}$ & $\begin{array}{l}\text { Tecnologías ambientales: } \\
\text { - Tecnologías y productos menos contaminantes y más } \\
\text { eficientes en el uso de los recursos }\end{array}$ \\
\hline
\end{tabular}


Cuadro 2 (continuación)

\begin{tabular}{ll}
$\begin{array}{l}\text { Código } \\
\text { del SA 2002 }\end{array}$ & Descripción \\
\hline 7324 & $\begin{array}{l}\text { Artículos de higiene o tocador, y sus partes, de } \\
\text { fundición, hierro o acero }\end{array}$ \\
732490 & - Otros, incluidas las partes
\end{tabular}

- Otros, incluidas las partes
Categoría y subcategoría

\section{Gestión de residuos y tratamiento de agua:}

- Gestión de las aguas residuales y tratamiento del agua potable

Captura y almacenamiento de carbono

Tecnologías ambientales:

- Tecnologías para el consumo eficiente de energía

\author{
Captura y almacenamiento de carbono \\ Tecnologías ambientales: \\ - Tecnologías para el consumo eficiente de energía \\ Gestión de residuos y tratamiento de agua: \\ - Gestión de residuos sólidos y peligrosos y sistemas de \\ reciclaje \\ - Gestión de residuos, reciclado y restauración del medio \\ ambiente
}

\section{Gestión de residuos y tratamiento de agua:}

- Gestión de residuos, reciclado y restauración del medio ambiente

- Gestión de residuos sólidos y peligrosos y sistemas de reciclaje

Captura y almacenamiento de carbono

Tecnologías ambientales:

- Tecnologías para el consumo eficiente de energía

\begin{abstract}
8405 Generadores de gas pobre (gas de aire) o de gas de agua, incluso con sus depuradores; generadores de acetileno y generadores similares de gases, por vía húmeda, incluso con sus depuradores

840510 - Generadores de gas pobre (gas de aire) o de gas de agua, incluso con sus depuradores; generadores de acetileno y generadores similares de gases, por vía húmeda, incluso con sus depuradores
\end{abstract}

\begin{tabular}{|c|c|c|}
\hline 8406 & Turbinas de vapor & \\
\hline 840681 & $\begin{array}{l}\text { - Turbinas para la propulsión de barcos: de potencia } \\
\text { superior a } 40 \mathrm{MW}\end{array}$ & Energía renovable \\
\hline 8409 & $\begin{array}{l}\text { Partes identificables como destinadas, exclusiva o } \\
\text { principalmente, a los motores de las partidas } 84.07 \\
\text { u } 84.08\end{array}$ & \\
\hline 840999 & - Otras: otras & $\begin{array}{l}\text { Control de la contaminación atmosférica } \\
\text { Tecnologías ambientales: } \\
\text { - Tecnologías para el consumo eficiente de energía } \\
\text { Reducción de los ruidos y las vibraciones } \\
\text { Captura y almacenamiento de carbono }\end{array}$ \\
\hline
\end{tabular}

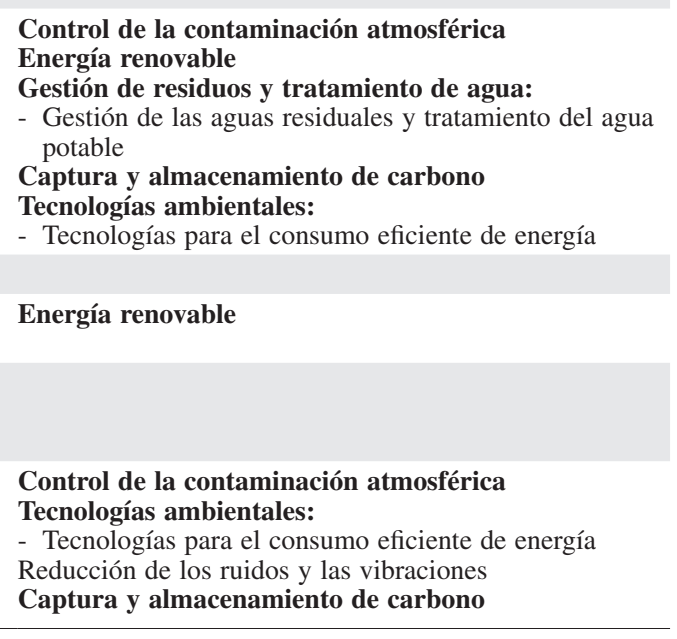


Cuadro 2 (continuación)

\begin{tabular}{|c|c|c|}
\hline $\begin{array}{l}\text { Código } \\
\text { del SA } 2002\end{array}$ & Descripción & Categoría y subcategoría \\
\hline 8410 & $\begin{array}{l}\text { Turbinas hidráulicas, ruedas hidráulicas y sus } \\
\text { reguladores }\end{array}$ & \\
\hline 841011 & $\begin{array}{l}\text { - Turbinas y ruedas hidráulicas, de potencia inferior o } \\
\text { igual a } 1000 \mathrm{~kW}\end{array}$ & $\begin{array}{l}\text { Energía renovable } \\
\text { Tecnologías ambientales: } \\
\text { - Tecnologías para el consumo eficiente de energía } \\
\text { Captura y almacenamiento de carbono }\end{array}$ \\
\hline 841012 & $\begin{array}{l}\text { - Turbinas y ruedas hidráulicas de potencia superior } \\
\text { a } 1000 \mathrm{~kW} \text {, pero inferior o igual a } 10000 \mathrm{~kW}\end{array}$ & $\begin{array}{l}\text { Tecnologías ambientales: } \\
\text { - Tecnologías para el consumo eficiente de energía } \\
\text { Captura y almacenamiento de carbono }\end{array}$ \\
\hline 841090 & $\begin{array}{l}\text { - Turbinas hidráulicas, ruedas hidráulicas y sus } \\
\text { reguladores; partes, incluidos los reguladores }\end{array}$ & $\begin{array}{l}\text { Energía renovable } \\
\text { Tecnologías ambientales: } \\
\text { - Tecnologías para el consumo eficiente de energía } \\
\text { Captura y almacenamiento de carbono }\end{array}$ \\
\hline 8411 & Turborreactores, turbopropulsores y demás turbinas de gas & \\
\hline 841181 & $\begin{array}{l}\text { - Otras turbinas de gas, de potencia inferior o igual } \\
\text { a } 5000 \mathrm{~kW}\end{array}$ & $\begin{array}{l}\text { Energía renovable } \\
\text { Tecnologías ambientales: } \\
\text { - Tecnologías para el consumo eficiente de energía } \\
\text { Captura y almacenamiento de carbono } \\
\text { Otros: } \\
\text { - Productos ambientalmente preferibles según su uso } \\
\quad \text { final o las características de su eliminación }\end{array}$ \\
\hline 841182 & Otras turbinas de gas, de potencia superior a $5000 \mathrm{~kW}$ & $\begin{array}{l}\text { Energía renovable } \\
\text { Tecnologías ambientales: } \\
\text { Tecnologías para el consumo eficiente de energía } \\
\text { Captura y almacenamiento de carbono } \\
\text { Otros: } \\
\text { - Productos ambientalmente preferibles según su uso } \\
\quad \text { final o las características de su eliminación }\end{array}$ \\
\hline 8418 & $\begin{array}{l}\text { Refrigeradores, congeladores y demás material, } \\
\text { máquinas y aparatos para producción de frío, aunque } \\
\text { no sean eléctricos; bombas de calor, excepto las } \\
\text { máquinas y aparatos para acondicionamiento de aire } \\
\text { de la partida } 84.15\end{array}$ & \\
\hline 841861 & $\begin{array}{l}\text { - Otros equipos de refrigeración o congelación; bombas } \\
\text { de calor: grupos frigoríficos de compresión en los que } \\
\text { el condensador esté constituido por un intercambiador } \\
\text { de calor }\end{array}$ & Energía renovable \\
\hline 8419 & $\begin{array}{l}\text { Aparatos y dispositivos, aunque se calienten } \\
\text { eléctricamente (excepto los hornos y demás aparatos } \\
\text { de la partida } 85.14) \text {, para el tratamiento de materias } \\
\text { mediante operaciones que impliquen un cambio de } \\
\text { temperatura, tales como calentamiento, cocción o } \\
\text { torrefacción }\end{array}$ & \\
\hline 841919 & $\begin{array}{l}\text { Calentadores de agua de calentamiento instantáneo o de } \\
\text { acumulación, excepto los eléctricos: Otros }\end{array}$ & Energía renovable \\
\hline 841950 & - Intercambiadores de calor & $\begin{array}{l}\text { Energía renovable } \\
\text { Tecnologías ambientales: } \\
\text { - Reducción de las emisiones de la quema de gas } \\
\text { - Tecnologías para el consumo eficiente de energía } \\
\text { - Gestión del calor y la energía } \\
\text { Captura y almacenamiento de carbono }\end{array}$ \\
\hline 8479 & $\begin{array}{l}\text { Máquinas y aparatos mecánicos con función propia, } \\
\text { no expresados ni comprendidos en otra parte de este } \\
\text { capítulo }\end{array}$ & \\
\hline 847989 & - Otras máquinas y aparatos: Otros & $\begin{array}{l}\text { Control de la contaminación atmosférica } \\
\text { Gestión de residuos y tratamiento de agua: } \\
\text { - Gestión de residuos sólidos y peligrosos y sistemas de } \\
\text { reciclaje } \\
\text { Energía renovable } \\
\text { Otros: } \\
\text { Productos y fuentes de energía renovables }\end{array}$ \\
\hline
\end{tabular}


Cuadro 2 (conclusión)

\begin{tabular}{|c|c|c|}
\hline $\begin{array}{l}\text { Código } \\
\text { del sA } 2002\end{array}$ & Descripción & Categoría y subcategoría \\
\hline 8502 & Grupos electrógenos y convertidores rotativos eléctricos & \\
\hline 850231 & - Otros grupos electrógenos: de energía eólica & $\begin{array}{l}\text { Energía renovable } \\
\text { Otros: } \\
\text { - Productos y fuentes de energía renovables }\end{array}$ \\
\hline 8504 & $\begin{array}{l}\text { Transformadores eléctricos, convertidores eléctricos } \\
\text { estáticos (por ejemplo: rectificadores) y bobinas de } \\
\text { reactancia (autoinducción). }\end{array}$ & \\
\hline 850410 & $\begin{array}{l}\text { - Balastos (reactancias) para lámparas o tubos de } \\
\text { descarga }\end{array}$ & $\begin{array}{l}\text { Tecnologías ambientales: } \\
\text { - Tecnologías para el consumo eficiente de energía } \\
\text { Captura y almacenamiento de carbono }\end{array}$ \\
\hline 8537 & $\begin{array}{l}\text { Cuadros, paneles, consolas, armarios y demás soportes } \\
\text { equipados con varios aparatos de las partidas } 85.35 \\
\text { u } 85.36 \text {, para control o distribución de electricidad, } \\
\text { incluidos los que incorporen instrumentos o aparatos } \\
\text { del capítulo 90, así como los aparatos de control } \\
\text { numérico, excepto los aparatos de conmutación de la } \\
\text { partida } 85.17\end{array}$ & \\
\hline 853710 & - Para una tensión inferior o igual a $1000 \mathrm{~V}$ & Energía renovable \\
\hline 8541 & $\begin{array}{l}\text { Diodos, transistores y dispositivos semiconductores } \\
\text { similares; dispositivos semiconductores fotosensibles, } \\
\text { incluidas las células fotovoltaicas, aunque estén } \\
\text { ensambladas en módulos o paneles; diodos emisores de } \\
\text { luz; cristales piezoeléctricos montados. }\end{array}$ & \\
\hline 854140 & $\begin{array}{l}\text { - Dispositivos semiconductores fotosensibles, incluidas } \\
\text { las células fotovoltaicas, aunque estén ensambladas } \\
\text { en módulos o paneles; diodos emisores de luz }\end{array}$ & $\begin{array}{l}\text { Energía renovable } \\
\text { Otros: } \\
\text { - Productos y fuentes de energía renovables }\end{array}$ \\
\hline 9001 & $\begin{array}{l}\text { Fibras ópticas y haces de fibras ópticas; cables de fibras } \\
\text { ópticas, excepto los de la partida } 85.44 \text {; hojas y placas } \\
\text { de materia polarizante; lentes (incluso de contacto), } \\
\text { prismas, espejos y demás elementos de óptica de } \\
\text { cualquier materia, sin montar, excepto los de vidrio sin } \\
\text { trabajar ópticamente }\end{array}$ & \\
\hline 900190 & - Otros & Energía renovable \\
\hline 9002 & $\begin{array}{l}\text { Lentes, prismas, espejos y demás elementos de óptica } \\
\text { de cualquier materia, montados, para instrumentos o } \\
\text { aparatos, excepto los de vidrio sin trabajar ópticamente. }\end{array}$ & \\
\hline 900290 & - Otros & Energía renovable \\
\hline 9027 & $\begin{array}{l}\text { Instrumentos y aparatos para análisis físicos o } \\
\text { químicos (por ejemplo: polarímetros, refractómetros, } \\
\text { espectrómetros, analizadores de gases o humos); } \\
\text { instrumentos y aparatos para ensayos de viscosidad, } \\
\text { porosidad, dilatación, tensión superficial o similares o } \\
\text { para medidas calorimétricas, acústicas o fotométricas } \\
\text { (incluidos los exposímetros); micrótomos. }\end{array}$ & \\
\hline 902730 & $\begin{array}{l}\text { - Espectrómetros, espectrofotómetros y espectrógrafos } \\
\text { que utilicen radiaciones ópticas (UV, visibles, IR) }\end{array}$ & $\begin{array}{l}\text { Tecnologías ambientales: } \\
\text { - Equipo de vigilancia, análisis y evaluación del medio } \\
\text { ambiente }\end{array}$ \\
\hline 9032 & $\begin{array}{l}\text { Instrumentos y aparatos para regulación o control } \\
\text { automáticos }\end{array}$ & \\
\hline 903210 & - Termostatos & $\begin{array}{l}\text { Tecnologías ambientales: } \\
\text { - Equipo de vigilancia, análisis y evaluación del medio } \\
\text { ambiente } \\
\text { Reducción de las emisiones de la quema de gas } \\
\text { - Tecnologías para el consumo eficiente de energía } \\
\text { Captura y almacenamiento de carbono }\end{array}$ \\
\hline
\end{tabular}

Fuente: Organización Mundial del Comercio (омc), Report by the Chairman, Ambassador Manuel A.J. Teehankee, to the Trade Negotiations Committee, Ginebra, Comité de Comercio y Medio Ambiente, 2011.

SA: Sistema Armonizado de Designación y Codificación de Mercancías. 


\section{III}

\section{Enfoque metodológico}

Como se mencionó en la sección anterior, la lista de posibles bienes y servicios verdes es extensa y polémica. Para que la lista de posibles esferas de actividad comercial no sea arbitraria, o incluso para evitar que se convierta en una lista exhaustiva que no sería necesariamente pertinente a la situación de Barbados, se ha empleado un método analítico para evaluar dichas esferas de actividad. En el gráfico 5 se muestra una representación esquemática de ese criterio. En el enfoque que se adopte, se debe tomar en consideración un universo de oportunidades de negocios verdes y, en vista de que el presente documento se centra en las oportunidades de exportación, la lista propuesta por la OMC (2011) constituye un buen punto de partida. Sin embargo, como en esa lista se excluyen los servicios (un ámbito en que Barbados probablemente tendría ventajas comparativas), el estudio también se vale de las listas de la Oficina de Estadísticas Laborales (2012) para generar una amplia base de datos acerca de las empresas verdes.

Una de las formas de determinar las posibles oportunidades de exportación para las empresas verdes es mediante el cálculo de los índices de ventaja comparativa revelada (Balassa, 1986 y 1989). Estos índices proporcionan una medición sencilla de hasta qué punto un país o grupo regional resulta más especializado en una esfera particular de bienes en relación con otro. El índice de ventaja comparativa que se utiliza más comúnmente es la ventaja revelada de las exportaciones (VRE):

$$
V R E=\frac{X_{i j} / \sum_{j=1}^{J} X_{i j}}{\sum_{n=1}^{N} X_{n j} / \sum_{n=1}^{N} \sum_{j=1}^{J} X_{i j}}
$$

donde $X_{i j}$ representa las exportaciones del producto $j$ realizadas por el país $i$, y $X_{n j}$ las exportaciones del mismo producto realizadas por el grupo de países $n$. Se supone que el país tiene una ventaja comparativa revelada si se cumple que VRE $>1$, y que tiene una desventaja comparativa revelada cuando $\mathrm{VRE}<1$.

Vollrath (1991) propone tres índices alternativos: i) la ventaja comercial relativa $(V C R)$; ii) el logaritmo de la ventaja relativa de las exportaciones $(\ln V R E)$, y

GRÁFICO 5

Representación esquemática de las oportunidades de exportación ecológica

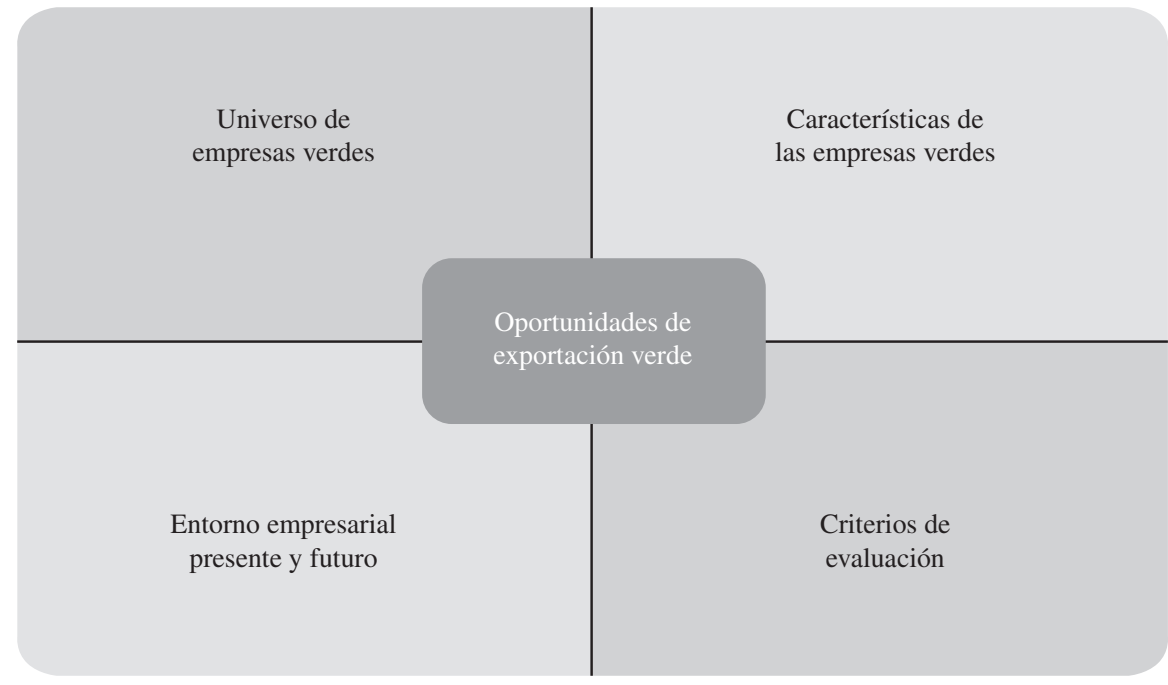

Fuente: elaboración del autor. 
iii) la competitividad revelada $(C R)$. Estos tres índices se determinan de la siguiente forma:

$$
\begin{gathered}
V R E=\frac{X_{i j} / \sum_{j=1}^{J} X_{i j}}{\sum_{n=1}^{N} X_{n j} / \sum_{n=1}^{N} \sum_{j=1}^{J} X_{i j}} \\
\frac{M_{i j} / \sum_{j=1}^{J} M_{i j}}{\sum_{-{ }_{1}}^{N} M_{n i} / \sum_{.-1}^{N} \sum_{:-1}^{J} M_{i ;}} \\
\ln V R E=\ln \left(\frac{X_{i j} / \sum_{j=1}^{J} X_{i j}}{\sum_{n=1}^{N} X_{n j} / \sum_{n=1}^{N} \sum_{j=1}^{J} X_{i j}}\right) \\
\ln \left(\frac{\ln \left(\begin{array}{c}
X_{i j} / \sum_{j=1}^{J} X_{i j} \\
\sum_{n=1}^{N} X_{n j} / \sum_{n=1}^{N} \sum_{j=1}^{J} X_{i j} / \sum_{n=1}^{N} \sum_{j=1}^{J} M_{i j}
\end{array}\right)-}{M_{i j} / \sum_{j=1}^{J} M_{i j}}\right)
\end{gathered}
$$

En los tres casos, los valores positivos indicarían que el país posee una ventaja comparativa revelada. Cabe señalar que todos los índices mencionados pueden resultar distorsionados debido a las políticas gubernamentales y otras intervenciones. Esta salvedad se debería tener en cuenta al interpretar los resultados. Todos los valores de las exportaciones e importaciones de productos se obtienen a partir de la Base de datos estadísticos sobre el comercio de mercaderías (COMTRADE), con arreglo a la clasificación de seis dígitos del sa 2002 y los datos del comercio correspondientes al período 2005-20104.

\footnotetext{
${ }^{4}$ Los códigos del Sistema Armonizado de Designación y Codificación de Mercancías (sA 2002) correspondientes al universo de bienes ambientales son:250300,271011, 271019,271111,271112, 271113, 271114, 271119,271121,271129, 281810,281820, 28183, 290911, 290919, 290920, 290930, 290941, 290942, 290943, 290944, 290949, 290950, 290960, 291411, 291412, 291413, 291419, 291421, 291422, 291423, 291429, 291431, 291440, 291450, 291461, 291469, 291470, 382490, 390210, 390220, 390230, 390290, 390799, 390910, 390920, 390930, 390940, 390950, 391110, 391190, 391211, 391212, 391220, 391231, 391239, 391290, 392010, 401699, 450410, 460120, 470710, 470720, 470730, 470790, 530310, 530410, 530490, 560314, 560710, 560721, 560811, 560890, 630510, 691010, 701931, 730300, 730410, 730421, 730431, 730439, 730441, 730449, 730451, 730459, 730490, 730511, 730512, 730519, 730520, 730531, 730539, 730590, 730610,
}

Debido a que la disponibilidad de datos sobre servicios internacionales es limitada, no fue posible realizar un análisis similar sobre las exportaciones de servicios. En su lugar, se efectuó un análisis de fuerzas, debilidades, oportunidades y amenazas (FODA) para determinar en qué medida coinciden las características de las empresas verdes con el entorno empresarial actual y el previsto para el futuro. De este modo, algunos elementos del entorno empresarial -como la existencia de una fuerza de trabajo debidamente capacitada y la situación en materia de licencias y permisos, infraestructura y finanzas- ponen de relieve las limitaciones que afectan a las nuevas empresas y que probablemente incidirán en su viabilidad. En este aspecto, el modelo se dificulta un tanto. Determinada característica podría constituir una limitación en el entorno empresarial actual pero, si fuera eliminada gracias a cambios futuros en las políticas, al final podría servir de estímulo a la actividad empresarial en el ámbito correspondiente.

730620, 730630, 730640, 730650, 730660, 730690, 730711, 730719, 730721, 730722, 730723, 730729, 730791, 730792, 730793, 730799, 730820, 730900, 731010, 731021, 731029, 731100, 732111, 732190, $732490,732510,732690,761100,761290,761300,840211,840212$, $840219,840220,840290,840310,840390,840410,840420,840490$, 840510, 840590, 840610, 840681, 840682, 840690, 840790, 840890, 840991, 840999, 841011, 841012, 841013, 841090, 841111, 841112, $841121,841122,841181,841182,841191,841199,841210,841221$, 841229, 841231, 841239, 841280, 841290, 841311, 841319, 841320, 841330, 841340, 841350, 841360, 841370, 841381, 841382, 841391, 841392, 841410, 841430, 841440, 841459, 841480, 841490, 841510, $841581,841610,841620,841630,841690,841780,841790,841810$, 841821, 841830, 841840, 841861, 841869, 841919, 841939, 841940, 841950, 841960, 841989, 841990, 842010, 842091, 842099, 842119, 842121, 842123, 842129, 842131, 842139, 842191, 842199, 842220, 842290, 842833, 842940, 846291, 846596, 846599, 846694, 847130, 847160, 847170, 847410, 847420, 847431, 847432, 847439, 847480, $847490,847710,847720,847730,847740,847751,847759,847780$, 847790, 847920, 847982, 847989, 847990, 848110, 848120, 848130, $848140,848180,848190,848210,848220,848230,848240,848250$, $848280,848291,848299,848340,848360,850161,850162,850163$, $850164,850231,850239,850300,850410,850421,850422,850423$, $850431,850432,850433,850434,850440,850450,850490,850511$, $850519,850520,850530,850590,850610,850630,850640,850650$, $850660,850680,850690,850720,850740,850780,850790,850980$, $851140,851150,851180,851190,851410,851420,851430,851440$, $851490,851629,851711,851721,851730,851750,851840,852090$, $852190,852210,852390,852540,852691,852812,852821,852830$, 853661, 853710, 853949, 854140, 854389, 854390, 870210, 870290, $870321,870322,870323,870324,870331,870332,870333,870390$, $870410,870421,870422,870423,870431,870432,870490,870510$, 870520, 870530, 870540, 870590, 871110, 871120, 871130, 871140, 871150, 890790, 900190, 900290, 901510, 901520, 901530, 901540, 901580, 901590, 902410, 902480, 902490, 902511, 902519, 902580, 902590, 902610, 902620, 902680, 902690, 902710, 902720, 902730, 902740, 902750, 902780, 902790, 902810, 902820, 902830, 902890, 903010, 903020, 903031, 903039, 903040, 903082, 903083, 903089 , 903090, 903110, 903120, 903130, 903140, 903149, 903180, 903190, 903210, 903220, 903281, 903289, 903290, 903300, 940510, 940520, 940540 y 950720 . 
Según el enfoque descrito por Porter (2000), se elaboraron criterios de evaluación sencillos para examinar en qué medida coincide cada categoría posible de exportaciones ecológicas con el entorno empresarial local. Se asignó una puntuación de 1 a 11 a cada producto o categoría de servicios de acuerdo con la respuesta a las siguientes preguntas:

- ¿Se requiere alguna tecnología patentada? $(\mathrm{S} i ́=0$, No $=1)$

- ¿Barbados tiene acceso a los canales de distribución? $(\mathrm{S} i ́=0, \mathrm{No}=1)$

- ¿Barbados tiene acceso a materias primas y otros insumos (por ejemplo, mano de obra)? (Sí = 0, No $=1)$

- ¿Existen ventajas de costo independientemente de la escala? $($ Sí $=0$, No $=1)$
- ¿Son moderados los requisitos de capital para las nuevas empresas? $($ Sí $=0$, No $=1)$

- ¿Ya existen normas de productos o normas tecnológicas? $($ Sí $=0$, No $=1$ )

- ¿Hay obstáculos reglamentarios con los que tropezarían las nuevas empresas potenciales? $($ Sí $=0$, No = 1)

- ¿Es probable que haya deseconomías de escala en la producción? ( $\mathrm{Sí}=0, \mathrm{No}=1)$

- ¿Existen ayudas del gobierno? $(\mathrm{S} i ́=0, \mathrm{No}=1)$

- ¿Hay un número pequeño de posibles sustitutos o competidores? ( $\mathrm{Sí}=0, \mathrm{No}=1$ )

- ¿Existen pocos obstáculos para la salida? ( Sí $^{-}$0, No $=1$ )

La puntuación final de cada grupo de productos se determinó mediante la suma de las puntuaciones obtenidas en cada una de las preguntas anteriores.

\section{IV}

\section{Clasificación de las posibles oportunidades en materia de exportación verde}

A fin de evaluar la coherencia de los índices de ventaja comparativa revelada, se calcularon las estadísticas de correlación entre pares de los cuatro indicadores. En general, todos los indicadores mantienen correlaciones positivas: si un índice de ventaja comparativa da a entender que el país tiene una ventaja respecto de un producto determinado, es probable que los demás indicadores también proporcionen un resultado similar. Además de la relación positiva, todas las estadísticas de correlación bivariada fueron superiores a 0,7 , lo que indica un alto nivel de coherencia en los resultados.

Dada dicha coherencia, en el cuadro 3 solo se muestra el promedio de los índices de competitividad revelada (CR) durante el período 2005-2010. Los resultados dan a entender que Barbados mantiene una ventaja en lo que respecta a la competitividad revelada de 24 productos en distintas categorías de bienes verdes (véase el cuadro 3).

Sobre la base de este análisis, Barbados posee ventaja comparativa solo en el $6 \%$ de los productos verdes que figuran en el universo referencial de bienes ambientales de la OMc. Teniendo en cuenta el tamaño de la isla, no es probable que sea un productor importante de un conjunto diverso de bienes. No obstante, el hecho de que la isla explota en escasa medida las oportunidades relacionadas con la exportación de productos verdes da a entender que aún queda un amplio margen de crecimiento. Tal conclusión encuentra mayor sustento en las tendencias recientes en cuanto a la exportación de productos verdes. Con el objetivo de evaluar hasta qué punto la isla ha explotado estas ventajas, en el gráfico 6 se delimita el valor de las exportaciones de productos verdes de Barbados en el período 2007-2009. Los resultados apuntan a que esas exportaciones siguen representando apenas una pequeña proporción de las exportaciones totales de mercancías de la isla: entre el $3 \%$ y el $4 \%$. Además, la contribución de las exportaciones de productos verdes a las exportaciones totales de mercancías no ha cambiado de manera apreciable. Para beneficiarse plenamente de la demanda mundial de productos verdes, la promoción de las exportaciones en estas áreas será fundamental en los próximos años. 
CUADRO 3

Índices de ventaja comparativa revelada respecto de los productos verdes

\begin{tabular}{|c|c|c|c|}
\hline $\begin{array}{l}\text { Código } \\
\text { del SA } 2002\end{array}$ & Producto & Categoría y subcategoría de productos verdes & $\begin{array}{l}\text { Indice de } \\
\text { competitividad } \\
\text { revelada }(\mathrm{CR})\end{array}$ \\
\hline 847780 & - Otras máquinas y aparatos & $\begin{array}{l}\text { Tecnologías ambientales: } \\
\text { Tecnologías para el consumo eficiente de energía } \\
\text { Captura y almacenamiento de carbono }\end{array}$ & 5,545 \\
\hline 470790 & $\begin{array}{l}\text { - Otros, incluidos los desperdicios y } \\
\text { desechos sin clasificar }\end{array}$ & $\begin{array}{l}\text { Energía renovable } \\
\text { Otros: } \\
\text { Productos y fuentes de energía renovables }\end{array}$ & 4,802 \\
\hline 731029 & $\begin{array}{l}\text { - De capacidad inferior a } 50 \text { litros: } \\
\text { Otros }\end{array}$ & $\begin{array}{l}\text { Gestión de residuos y tratamiento de agua: } \\
\text { - Gestión de las aguas residuales y tratamiento del agua potable }\end{array}$ & 3,429 \\
\hline 841960 & $\begin{array}{l}\text { - Aparatos y dispositivos para } \\
\text { licuefacción de aire u otros gases }\end{array}$ & Control de la contaminación atmosférica & 3,071 \\
\hline 847730 & - Máquinas de moldear por soplado & $\begin{array}{l}\text { Tecnologías ambientales: } \\
\text { - Tecnologías para el consumo eficiente de energía } \\
\text { Captura y almacenamiento de carbono }\end{array}$ & 2,857 \\
\hline 271129 & - Otros, en estado gaseoso & $\begin{array}{l}\text { Tecnologías ambientales: } \\
\text { - Reducción de las emisiones de la quema de gas } \\
\text { - Tecnologías para el consumo eficiente de energía } \\
\text { Captura y almacenamiento de carbono }\end{array}$ & 2,515 \\
\hline 841919 & $\begin{array}{l}\text { - Calentadores de agua de calentamiento } \\
\text { instantáneo o de acumulación, excepto } \\
\text { los eléctricos: Otros }\end{array}$ & Energía renovable & 2,458 \\
\hline 850660 & - Pilas y baterías de pilas, de aire-zinc & $\begin{array}{l}\text { Energía renovable } \\
\text { Otros: } \\
\text { - Productos y fuentes de energía renovables }\end{array}$ & 1,974 \\
\hline 840290 & - Partes & $\begin{array}{l}\text { Tecnologías ambientales: } \\
\text { - Tecnologías para el consumo eficiente de energía } \\
\text { Captura y almacenamiento de carbono }\end{array}$ & 1,924 \\
\hline 841940 & - Aparatos de destilación o rectificación & $\begin{array}{l}\text { Gestión de residuos y tratamiento de agua: } \\
\text { - Gestión de residuos sólidos y peligrosos y sistemas de reciclaje }\end{array}$ & 1,762 \\
\hline 850162 & $\begin{array}{l}\text { - Generadores de corriente alterna } \\
\text { (alternadores), de potencia superior a } \\
75 \mathrm{kVA} \text {, pero inferior o igual a } 375 \\
\text { kVA }\end{array}$ & Energía renovable & 1,729 \\
\hline 291421 & $\begin{array}{l}\text { - Cetonas ciclánicas, ciclénicas o } \\
\text { cicloterpénicas, sin otras funciones } \\
\text { oxigenadas: alcanfor }\end{array}$ & $\begin{array}{l}\text { Tecnologías ambientales: } \\
\text { - Reducción de las emisiones de la quema de gas } \\
\text { - Tecnologías para el consumo eficiente de energía } \\
\text { Captura y almacenamiento de carbono }\end{array}$ & 1,702 \\
\hline 841340 & - Bombas para hormigón & $\begin{array}{l}\text { Tecnologías ambientales: } \\
\text { - Tecnologías para el consumo eficiente de energía } \\
\text { Captura y almacenamiento de carbono }\end{array}$ & 1,666 \\
\hline 730459 & $\begin{array}{l}\text { - Otros, de sección circular, de los } \\
\text { demás aceros aleados: Otros }\end{array}$ & $\begin{array}{l}\text { Gestión de residuos y tratamiento de agua: } \\
\text { - Gestión de las aguas residuales y tratamiento del agua potable }\end{array}$ & 1,516 \\
\hline 841382 & - Elevadores de líquidos & $\begin{array}{l}\text { Tecnologías ambientales: } \\
\text { - Tecnologías para el consumo eficiente de energía } \\
\text { Captura y almacenamiento de carbono }\end{array}$ & 1,483 \\
\hline 846291 & - Otras: prensas hidráulicas & $\begin{array}{l}\text { Gestión de residuos y tratamiento de agua: } \\
\text { - Gestión de residuos sólidos y peligrosos y sistemas de reciclaje }\end{array}$ & 1,345 \\
\hline 392010 & - De polímeros de etileno & $\begin{array}{l}\text { Gestión de residuos y tratamiento de agua: } \\
\text { - Gestión de residuos sólidos y peligrosos y sistemas de reciclaje }\end{array}$ & 0,681 \\
\hline 530310 & $\begin{array}{l}\text { - Yute y demás fibras textiles del líber, } \\
\text { en bruto o enriados }\end{array}$ & $\begin{array}{l}\text { Otros: } \\
\text { - Productos ambientalmente preferibles según su uso final o las } \\
\text { características de su eliminación }\end{array}$ & 0,473 \\
\hline
\end{tabular}


Cuadro 3 (conclusión)

\begin{tabular}{|c|c|c|c|}
\hline $\begin{array}{l}\text { Código } \\
\text { del SA } 2002\end{array}$ & Producto & Categoría y subcategoría de productos verdes & $\begin{array}{l}\text { Índice de } \\
\text { competitividad } \\
\text { revelada }(\mathrm{CR})\end{array}$ \\
\hline 732690 & - Otras & $\begin{array}{l}\text { Gestión de residuos y tratamiento de agua: } \\
\text { - Gestión de las aguas residuales y tratamiento del agua potable }\end{array}$ & 0,442 \\
\hline 850239 & $\begin{array}{l}\text { - Otros grupos electrógenos: } \\
\text { Otros }\end{array}$ & Energía renovable & 0,331 \\
\hline 847432 & $\begin{array}{l}\text { - Máquinas y aparatos de mezclar, } \\
\text { amasar o sobar: máquinas de mezclar } \\
\text { materia mineral con asfalto }\end{array}$ & $\begin{array}{l}\text { Tecnologías ambientales: } \\
\text { - Tecnologías para el consumo eficiente de energía } \\
\text { Captura y almacenamiento de carbono }\end{array}$ & 0,240 \\
\hline 731100 & $\begin{array}{l}\text { - Recipientes para gas comprimido o } \\
\text { licuado, de fundición, hierro o acero }\end{array}$ & $\begin{array}{l}\text { Tecnologías ambientales: } \\
\text { - Tecnologías para el consumo eficiente de energía } \\
\text { Captura y almacenamiento de carbono }\end{array}$ & 0,120 \\
\hline 841319 & $\begin{array}{l}\text { - Otras bombas para líquidos, incluso } \\
\text { con dispositivo medidor incorporado }\end{array}$ & $\begin{array}{l}\text { Tecnologías ambientales: } \\
\text { - Tecnologías para el consumo eficiente de energía } \\
\text { Captura y almacenamiento de carbono }\end{array}$ & 0,058 \\
\hline 560811 & $\begin{array}{l}\text { - De materia textil sintética o artificial: } \\
\text { redes confeccionadas para la pesca }\end{array}$ & $\begin{array}{l}\text { Otros: } \\
\text { - Protección de los recursos naturales }\end{array}$ & 0,016 \\
\hline
\end{tabular}

Fuente: elaboración del autor.

GRÁFICO 6

Barbados: valor de las exportaciones de productos verdes

(En millones de dólares y porcentajes de las exportaciones totales)

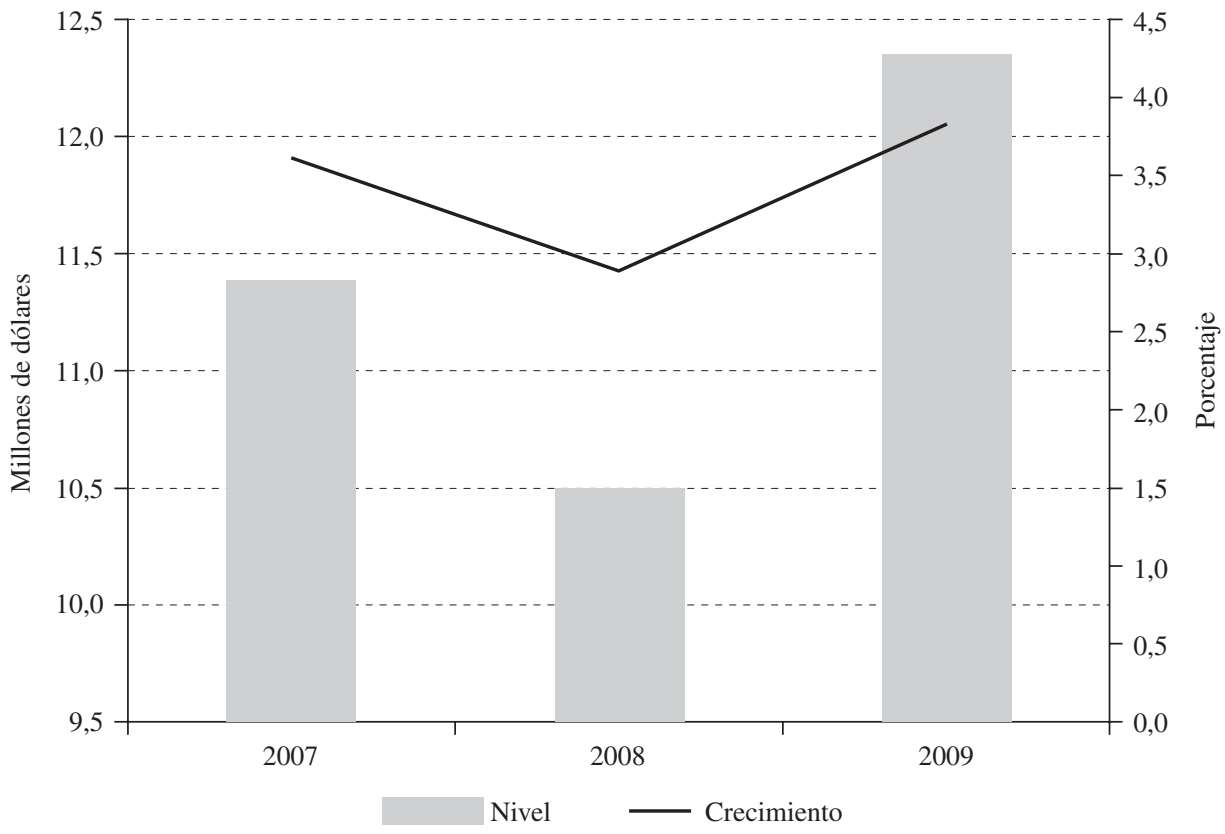

Fuente: Base de datos estadísticos sobre el comercio de mercaderías (COMTRADE). 
La lista del cuadro 3 se limitaba a los productos verdes pero, dado que los servicios representan la mayoría de las exportaciones de bienes y servicios de Barbados, es probable que la isla posea ventajas comparativas también en ese ámbito.

Los resultados indican posibles oportunidades en las esferas siguientes:

- Educación ambiental (plan de estudios para empleos verdes)

- Organizaciones dedicadas a la conservación del medio ambiente

- Gestión de programas sobre la atmósfera, el agua y los residuos

- Servicios de gestión de residuos

- Servicios de restauración (gestión de residuos)

- Operadores turísticos (excursiones verdes)

- Servicios de jardinería (servicios de jardinería de bajo consumo de energía)

- Empresas de publicidad y relaciones públicas

- Servicios de arquitectura (servicios de arquitectura relacionados con la certificación del programa Liderazgo en Energía y Diseño Ambiental (LEED, por sus siglas en inglés)
- Servicios de ingeniería (servicios de ingeniería para proyectos de energía renovable)

- Laboratorios de ensayo (servicios de ensayos ambientales)

- Servicios de diseño gráfico (para productos destinados a promover la sensibilidad ambiental)

- Contratistas (edificios con certificación LEED)

- Remodeladores de residencias (climatización)

- Construcción de edificios comerciales (edificios con certificación LEED)

Barbados ya cuenta con una numerosa fuerza de trabajo compuesta por personas capacitadas en la industria de servicios. No obstante, sus aptitudes se deben perfeccionar para poder aprovechar las oportunidades disponibles. En el gráfico 8 se muestra el desglose del empleo por ocupación y sexo a finales de 2011: de una población ocupada de 127.800 personas, cerca del $59 \%$ correspondería a trabajadores de servicios, un gran número de los cuales se dedicarían a profesiones de servicios de niveles superiores (por ejemplo, los técnicos y ocupaciones conexas).

En la actualidad, el Instituto Politécnico Samuel Jackman Prescod ofrece formación a nivel de diplomado

GRÁFICO 7

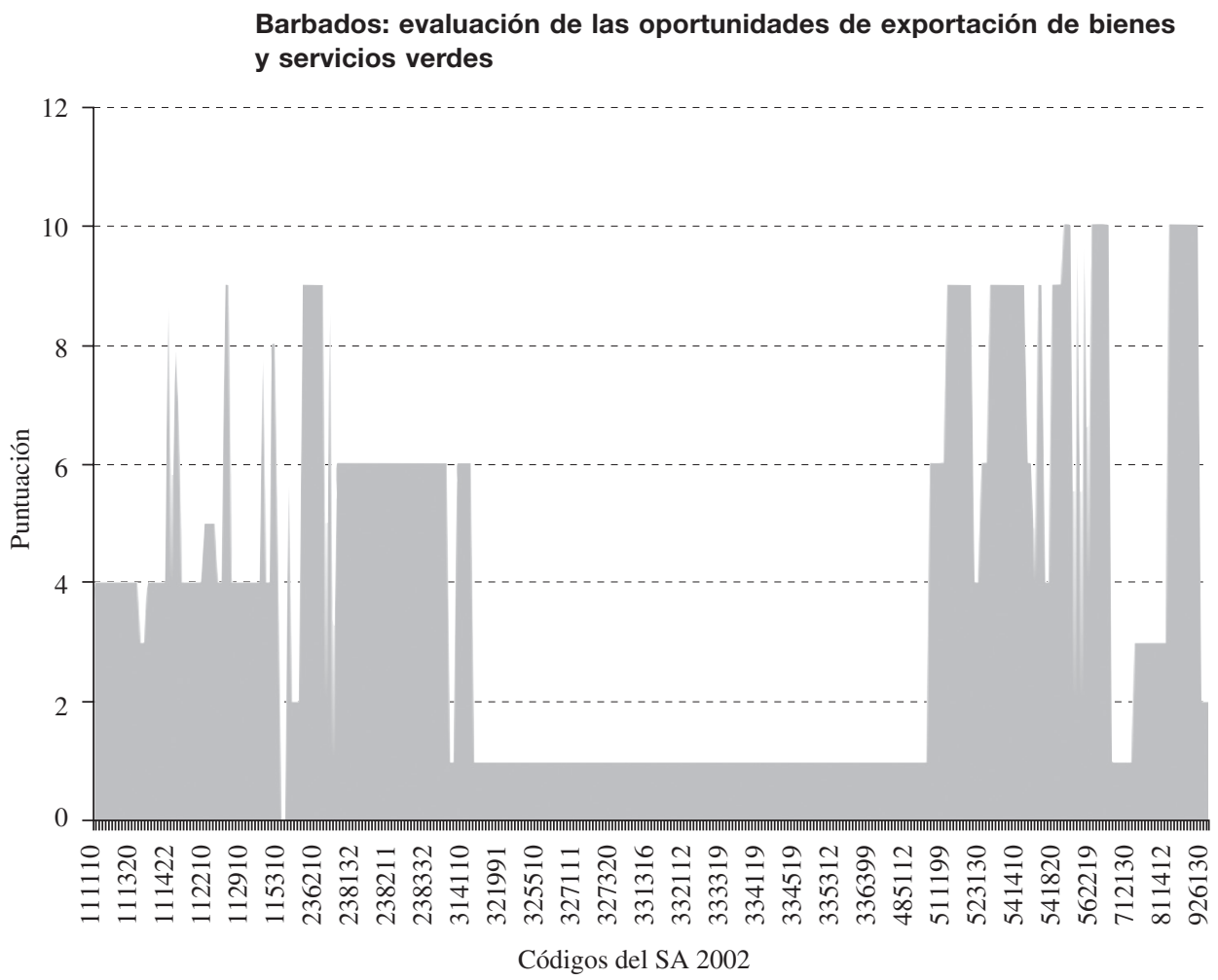

Fuente: elaboración del autor.

SA: Sistema Armonizado de Designación y Codificación de Mercancías. 
GRÁFICO 8

Barbados: empleo según ocupación y sexo

(En miles de personas)

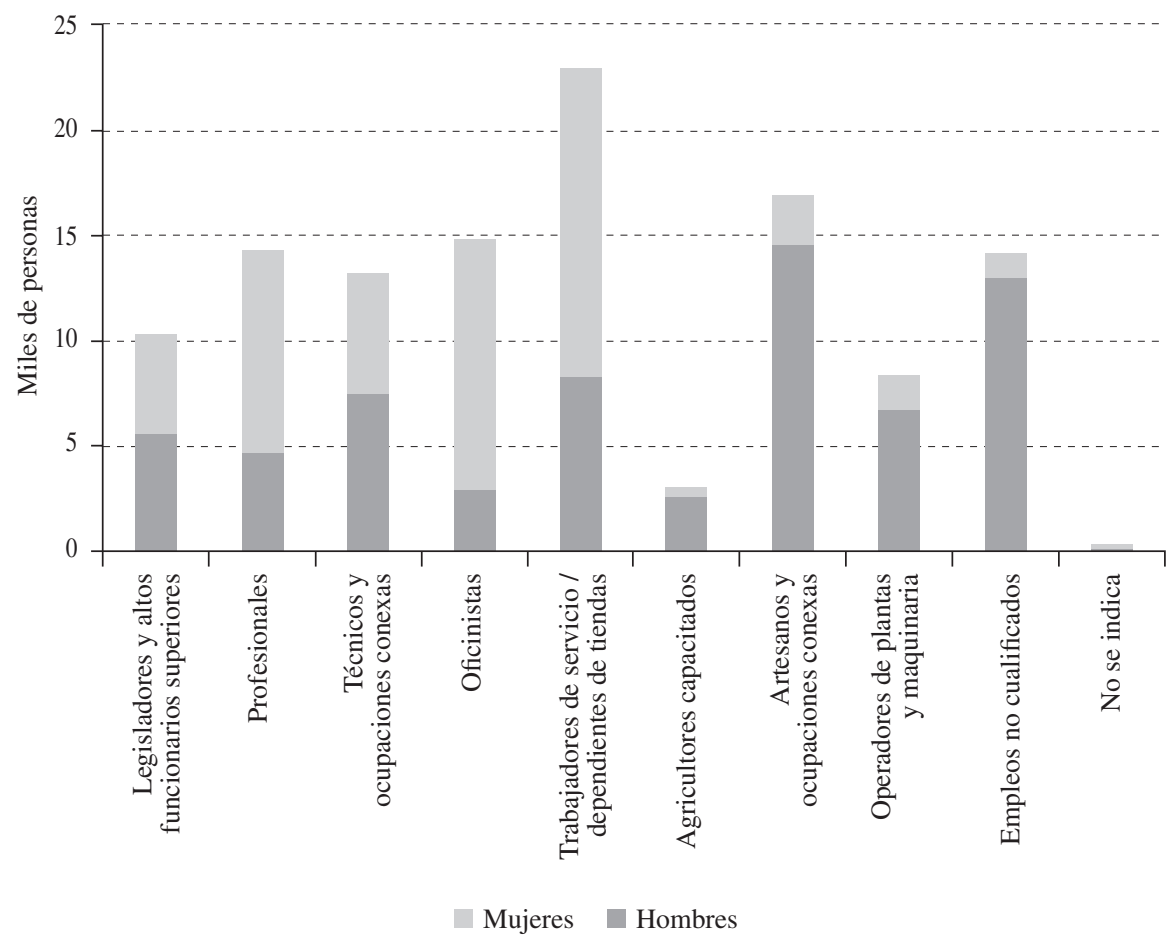

Fuente: Servicio de Estadística de Barbados.

en ingeniería mecánica, ingeniería eléctrica, construcción y estudios de arquitectura, entre otros temas, mientras que la Universidad de las Indias Occidentales ofrece estudios de pregrado y posgrado en los campus de Mona (Jamaica) y Saint Augustine (Trinidad y Tabago). Los estudiantes barbadenses que reúnan todos los requisitos pueden obtener becas completas del gobierno para realizar estudios en la Universidad de las Indias Occidentales.

No obstante, Barbados deberá hacer frente a algunas deficiencias en la capacitación para aprovechar con plenitud los beneficios potenciales de la exportación de servicios verdes. Por ejemplo, en la actualidad no existe un consejo local o regional para que los profesionales capacitados en servicios puedan solicitar certificaciones LEED para sus proyectos. Además, pese a los incentivos existentes que permiten a las empresas y a los particulares desgravar de impuestos parte del costo de la certificación Iso, los costos iniciales aún pueden resultar prohibitivos para muchas pequeñas empresas. 


\section{V}

\section{Conclusiones y recomendaciones}

Barbados se ha trazado metas ambiciosas con miras a la consecución de una economía verde. Dichas metas se basan en gran medida en el reconocimiento de que la isla debe hacer frente a importantes limitaciones de recursos y a la vulnerabilidad ante los aumentos bruscos de los precios de los recursos importados (Moore y otros, 2012). En el presente trabajo se evaluaron las posibles oportunidades de la isla en materia de exportación verde y se analizó la perspectiva de los bienes y servicios verdes. Mediante el uso de datos comerciales desagregados al nivel de seis dígitos (sistema de clasificación del sA 2002), se calcularon los índices de ventaja comparativa revelada para determinar las áreas en que la isla debería concentrar las ayudas. Dada la importancia de los servicios para la economía de Barbados, también se examinaron las oportunidades en materia de servicios verdes.

Los resultados del estudio dan a entender que Barbados posee una ventaja comparativa revelada en unas 16 categorías de exportaciones verdes. Sin embargo, el valor total de estas exportaciones es aún muy pequeño (menos del $4 \%$ de las exportaciones totales) y ha aumentado al mismo ritmo que las exportaciones totales en los últimos años. En relación con los servicios, resultó mayor el número de posibles áreas de actividad empresarial que permitirían aprovechar las aptitudes profesionales y recursos de la isla. No obstante, se necesitaría de todos modos cierto apoyo institucional para ayudar a estos profesionales a obtener certificación internacional.
También cabe destacar que las economías en desarrollo pueden introducir nuevos productos o exportaciones de servicios, pero mantenerse en esa actividad comercial es más difícil, ya que hay muchas empresas que experimentan dificultades para conservar su participación en el mercado. Estas empresas tienen que concentrarse en investigación y desarrollo (I+D) para mantener su participación en el mercado y aumentar la eficiencia.

Si bien los productos y servicios verdes podrían contribuir a diversificar la base de exportaciones de la isla, muchos de estos bienes y servicios pueden aprovechar las industrias existentes. Por ejemplo, las excursiones verdes pueden valerse de la infraestructura turística existente y ayudar a la isla a mejorar los ingresos de ese sector, al mismo tiempo que ofrecer a los visitantes una experiencia más satisfactoria. Barbados tiene un extenso historial en la producción de tecnologías solares (Moore y otros, 2012). Con una inversión suficiente, estas empresas podrían acceder a un mayor número de mercados de todo el mundo. Son solo algunos ejemplos, pero dan una idea de las posibles ventajas que se obtendrían al aprovechar los conocimientos y la experiencia obtenida en el país. También existirían ventajas potenciales si se siguiera una estrategia regional de desarrollo de la capacidad exportadora de bienes y servicios verdes. Por ejemplo, en lugar de crear instituciones de certificación en cada isla, podría desarrollarse una iniciativa regional en ese sentido. 


\section{Bibliografía}

Balassa, B. (1989), Comparative Advantage, Trade Policy and Economic Development, Nueva York, Harvester Wheatsheaf. (1986), "Comparative advantage in manufactured goods: a reappraisal", Review of Economics and Statistics, vol. 68, $\mathrm{N}^{\circ}$ 2, Cambridge, Massachusetts, The MIT Press.

Banco Mundial (2010), "Lessons from the Implementation of Republic of Korea's Green Stimulus", INFra Update [en línea] http://siteresources.worldbank.org/INTSDNET/ Resources/5944695-1247775731647/INFRA_Korea_ Newsletter.pdf.

Ernst y Young (2008), Comparative Advantage and Green Business, Londres, Ernst and Young.

Foro Económico Mundial (2011), The Global Competitiveness Report 2011-2012, Ginebra.

Huberty, M. y G. Zachmann (2011), Green Exports and the Global Product Space: Prospects for EU Industrial Policy, Bruselas, Bruegel.

Lall, S. (2001), "Competitiveness indices and developing countries: an economic evaluation of the global competitiveness report", World Development, vol. 29, $\mathrm{N}^{\circ}$ 9, Amsterdam, Elsevier.

Moore, W. y otros (2012), Green Economy Scoping Study Sythesis Report. Barbados, Bridgetown, Gobierno de Barbados/
Programa de las Naciones Unidas para el Medio Ambiente/ Universidad de las Indias Occidentales.

ocde/Eurostat (Organización de Cooperación y Desarrollo Económicos/Oficina de Estadística de las Comunidades Europeas) (1999), The Environmental Goods and Services Industry: Manual for Data Collection and Analysis, París, OECD Publishing.

Oficina de Estadísticas Laborales (2012), "Green Goods and Services", Departamento del Trabajo de los Estados Unidos [en línea] http://www.bls.gov/ggs/ggsoverview.htm.

OMC (Organización Mundial del Comercio) (2011), Report by the Chairman, Ambassador Manuel A.J. Teehankee, to the Trade Negotiations Committee, Ginebra, Comité de Comercio y Medio Ambiente.

Porter, M. (2000), Estrategia competitiva: Técnicas para el análisis de los sectores industriales y de la competencia, México, D.F., Grupo Editorial Patria.

Sinclair-Desgagné, B. (2008), "The environmental goods and services industry", International Review of Environmental and Resource Economics, vol. 2.

Vollrath, T. (1991), "A theoretical evaluation of alternative trade intensity measures of revealed comparative advantage", Review of World Economics, vol. 127, $\mathrm{N}^{\circ} 2$, Springer. 